Scientific Journal of October 6 University

ISSN (Print): 2314-8640

ISSN (Electronic): 2356-8119

Published by October 6 University (C) All Rights Reserved

Available online at: http:// sjou.journals.ekb.eg

Original Article
Citation: Khalifa et al., (2016). Physiological Studies on the Effect of Colde Wither and Thyrotropic Drugs on Some Reproductive Aspects. . Sci.J. of Oct. 6 Univ. 3(1), 33-40

Copyright: (C) 2016 Khalifa et al,. This is an open-access article distributed under the terms of the Creative Commons Attribution License, which permits unrestricted use, distribution, and reproduction in any medium, provided the original author and source are credited.

\title{
Physiological Studies on the Effect of Colde Wither and Thyrotropic Drugs on Some Reproductive Aspects
}

\author{
H.H. Khalifa ${ }^{1}$, M.A. Shehata ${ }^{1}$, H. M. Khalil ${ }^{1}$ and M.S.Hassan ${ }^{2}$ \\ ${ }^{1}$ Department of Animal Physiology, Faculty of Agriculture, Al-Zahra University. \\ ${ }^{2}$ Department of Animal Physiology at National Organization for Drug Control and Research (NODCAR).
}

\section{Received: 15-12-2014/ Revised: 20-12-2014 / Accepted: 15-01-2015}

\begin{abstract}
The thyroid gland is an endocrine gland synthesizes thyroid hormones, secreted into the blood stream and then carried to every tissue in the body. These thyroid hormones have a major impact on most body functions. For instances growth, use of energy and oxygen consumption, heat production, water and electrolytes homeostasis, modulate immunity, gonadal function and fertility and can alter the response the body toward different drugs. Hypothyroidism occurs when thyroxin levels drop to a point that the body begins to slow down its metabolic rate. Patients of hypothyroidism need to take compansatory thyroid hormones for the rest of their lives. The aim of present study is to investigate the effect of thyroid gland modulating drugs as (Eltroxin, thyroid hormone agonist and Carbimazol thyroid hormone antagonist) on the gonadal activity and reproduction aspects under the seasonal variation.
\end{abstract}

Key Words: Colde Wither, Thyrotropic, Broilers and thyroid gland.

\section{Introduction}

Nolpe $^{(1)}$ stated that carbimazol is a thiourea antithyroid drug act by blocking the production of thyroid hormones. Reinwein ${ }^{(2)}$ reported that carbimazol is given in an initial dose of 20 to 60 $\mathrm{mg}$ with supplemental levothyroxinee as a blocking-replacement regimen.

Valdemarsson $^{(3)}$ measured the lipoprotein concentrations and activities of lipoprotein lipase (LPL) and hepatic lipase (HL) in 70 subjects with thyroid function ranging from over hypothyroidism, over sub clinical hypothyroidism and euthyroidism to hyperthyroidism. It has been found that in parallel with serum T3 concentrations increasing from low in hypothyroidism too high in hyperthyroidism there were gradual increase in HL activities over the full spectrum of thyroid function, accompanied by decreasing levels of total and low density lipoprotein (LDL) cholesterol. High density lipoprotein (HDL) cholesterol was lower in hyperthyroidism than in euthyroidism but not significantly changed in the hypothyroid groups. The activity of LPL was decreased in over hypothyroidism compared to euthyroidism. But, in contrast to HL, the activity of LPL was not increased in hyperthyroidism. The results demonstrated that changes in HL activity seem to be an important mechanism for the disturbance of cholesterol metabolism in thyroid dysfunction.

Valdemarsson $^{(3)}$ showed that the serum triglycerides concentrations were elevated in over hypothyroidism but not changed in sub clinical hypothyroidism or in hyperthyroidism. Serdaru (4) investigated the physiological states by measuring levels of some serum metabolite in buffaloes. And showed the mean values of serum urea, creatinine and triglycerides were significantly higher in multipart animals than prim Para in each ambience whereas of cholesterol and glucose were significantly higher in primipara.

Tuffery and Redmond ${ }^{(5)}$ showed that after two days of administration of carbimazol $(0.1 \mathrm{~g} / 100 \mathrm{mg})$ in the drinking water of male rates $(200 \mathrm{~g}$ body weight for up to 24 weeks) the serum concentration of thyropin (TSH) was significantly increased, while the serum levels of tri-and tetra iodothyronine (T3 and T4) were decreased. Vinsova ${ }^{(6)}$ studied the effect of administration of carbimazol in the dose of 7.5 mumol /animal via a gastric tube for a period of one month on rats. They found that the serum level of TSH was not changed after administration of carbimazol in the given dose. Meanwhile, the 
content of cAMp in the thyroid gland was significantly increased after carbimazol treatment. Van Haaster ${ }^{(7)}$. Revealed that PTU treatment of wister rats from birth up to day 26 increased serum thyroid-stimulating hormone (TSH) levels and reduced serum levels of thyroxine (T4) from 5 days onwards, indicative of severe hypothyroidism. Sawaya and Lunn ${ }^{(8)}$ Indicated that administration of carbimazol caused lowering of the T3 plasma concentration. Morever, Cigankova and Bekeova ${ }^{(9)}$ found that when the experimental ram treated with Carbimazol the concentration of $\mathrm{T} 3$ decreased to lower physiological limit, and T4 concentration decreased to the hypothyroid level as compared to the control group. Patients with hyperthyroidism have decrease in lean body mass, which was regained after achievement of euthyroidism with carbimazole therapy. The hyperphagia accompanied with weight loss in hyperthyroidism was independent of leptin and ghrelin ${ }^{(10)}$.

Ayub and levell ${ }^{(11)}$ Showed that imidazole drugs had an inhibitory effect on androstendione and testosterone in adult rats. Turek ${ }^{(12)}$ Showed that neonatal treatment with the reversible goitrogen (PUT) results in a near do bling of spermatogenesis without effecting circulating testosterone levels in adult rats.

El-Wardany ${ }^{(13)}$ Reported thatan experiment was conducted to investigate the effect of controlled thyroid gland activity (Hyper or hypothyroidism) on energy utilization in broiler chickens. Two hundred and forty, one-day old, Cobb broiler chicks were distributed into three dietary metabolizable energy treatment groups (80 chicks each). The control group was fed basal diet (3150 kcal/ $\mathrm{kg}$ diet), the second group fed low metabolizable energy diet (minus $150 \mathrm{kcal} / \mathrm{kg}$ diet) with different thyroidal treatments and the third group fed very low metabolizable energy diet (minus $300 \mathrm{kcal} / \mathrm{kg}$ diet) with thyroidal treatments. Thyroidal treatments were applied at the beginning of the 2nd week, where was a control treatment, two hyperthyroidism groups induced by administration of eltroxin (T1) or calcium iodide (T2) and hypothyroidism group induced by carbimazole administration (T3). Results showed that plasma thyroidal hormones (T3, T4) concentrations and their ratio T3 / T4 showed considerable changes related to thyroidal treatments. Plasma glucagon's (G) level was significantly increased while insulin (I) level and I/G ratio were significantly decreased as affected by low energy diets. Carbimazole administration group had the lowest plasma insulin level and I/G ratio compared to other treatments. Moreover, calcium iodide significantly increased adenosinetriphosphate (ATP), Total adenylate (TA) and phosphate potential (PP) while carbimazole significantly decreased adenosine diphosphate (ADP) and adenosine monophosphate (AMP).
Histological examination of thyroid gland sections reflect the beneficial use of calcium iodide (CaI) as a safe additive without hazards effect on thyroid gland histology. Results suggested using calcium iodide to maximize the utilization of low energy diets, via its modulating action of thyroid gland activity. Hazelwood, R. L. ${ }^{(14)}$ Furthermore thyroid and pancreatic hormones involved in the regulation of growth, metabolism, heat production glycogen synthesis and storage and energy retrieval from body deposits when dietary energy intake does not meet the demands of tissues to perform their physiological functions.

Mandel ${ }^{(15)}$ Reported that levothyroxine is a thyroid hormone used as replacement therapy in the treatment of hypothyroidism. It is given in conditions such as diffuse nontoxic goiter and Hashimoto's thyroiditis to suppress the secretion of thyroid-stimulating hormone (TSH) and hence prevent or reverse enlargement of the thyroid gland. Levothyroxine is also used to suppress TSH production in the treatment of thyroid carcinoma and as a diagnostic agent for the differential diagnosis of hyperthyroidism. It is given with antithyroid in the blocking-replacement regiment for the management of hyperthyroidism. The peak therapeutic effect of regular oral levothyroxine may not achieved for several weeks and there is a slow response to changes in dosage. Similarly, effects

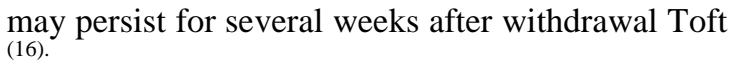

Valdemarsson $^{(3)}$ Measured the lipoprotein concentrations and activities of lipoprotein lipase (LPL) and hepatic lipase (HL) in 70 subjects with thyroid function ranging from over hypothyroidism, over sub clinical hypothyroidism and euthyroidism to hyperthyroidism. They reported that in parallel with serum T3 concentrations increasing from low in hypothyroidism to high in hyperthyroidism there were gradually higher HL activities over the full spectrum of thyroid function, accompanied by decreasing levels of total and low density lipoprotein (LDL) cholesterol. High density lipoprotein (HDL) cholesterol was lower $(\mathrm{P} \leq 0.05)$ in hyperthyroidism than in euthyroidism but not significantly changed in the hypothyroid groups. The activity of LPL was decreased $(\mathrm{P} \leq 0.001)$ in over hypothyroidism compared to euthyroidism. But, in contrast to HL, the activity of LPL was not increased in hyperthyroidism. Their results demonstrated that changes in HL activity seem to be an important mechanism for the disturbance of cholesterol metabolism in thyroid dysfunction.

Hansson $^{(17)}$ Studied the effects of triiodothyronine administration (20-40 micrograms three times daily over one week) in six healthy young men, showed that plasma cholesterol concentrations decreased by about $20 \%$ ( $p \leq 0.025)$, whereas there was a fall in plasma cholesterol could be accounted for by a 
reduction of HDL cholesterol $(-11 \%, \mathrm{p} \leq 0.025)$ as well as LDL cholesterol $(-27 \%, \mathrm{p} \leq 0.025)$.

Boston $^{(18)}$ Evaluated the glucose and lipid metabolism in healthy adult horses administered levothyroxine sodium (L-T4). Eight horses received an incrementally increasing dosage of L$\mathrm{T} 4(24,48,72$, or $96 \mathrm{mg}$ of L-T4/d) for weeks 1 to 8. Each dose was providing between $7 \mathrm{AM}$ and 8 $\mathrm{AM}$ in the morning grain meal for 2 weeks. Four additional horses remained untreated. They found that plasma TG concentration significantly decreased over time in treated horses. Hansson ${ }^{(17)}$. Studied the effects of triiodothyronine administration (20-40 micrograms three times daily over one week) in six healthy young men, showed that no change in plasma triglyceride levels occurred.

Mandel $^{(15)}$ reported that levothyroxine is used to suppress the secretion of thyroid-stimulating hormone (TSH) and hence prevent or reverse enlargement of the thyroid gland. Ganong (1995). Stated that thyroid function is regulated primarily by variations in the circulating level of TSH and the TSH secretion inhibited in a negative feedback fashion by circulating free T4 and T3. Dubey ${ }^{(20)}$ showed that increased concentrations of $\mathrm{T} 3$ and $\mathrm{T} 4$ were recorded in L-thyroxine-treated rats.

Weeiss and Burns ${ }^{(21)}$ The present study was conducted to determine whether hypothyroidism in adult male raw rats induced infertility by impairing sexual behavior or testicular function, whether the infertility could be reversed by thyroxin (T4) treatment, and whether the mutant could be produced by infertile raw rats via in vitro fertilization. The sexual behavior was analyzed by pairing with normal female rats. The fertility of epididymal sperm was determined by in vitro fertilization. The results indicated that the infertility resulted from both defective sexual behavior and testicular function. No untreated rdw rats mated. The weights of epididymides were significantly low, whereas those of testes were not different from those of untreated normal rats. Epididymal sperm with cytoplasm droplets were observed at a significantly high frequency. No fertilization was detected either in vivo or in vitro. Thyroxin treatment markedly increased serum $\mathrm{T} 4$ levels and the weights of both epididymides and testes. Partial reversion of the impaired sexual behavior was observed, and the percentage of epididymal sperm with cytoplasmic droplets was markedly decreased after T4 treatment. Fertility of epididymal sperm was completely reversed when determined both in vivo and in vitro, and homozygous embryos developed to term after transfer without loss of viability. Several investigators have reported studies on the role of thyroid hormones in reproductive tract growth and function. However, the effects of thyroid hormone deficiency on the developing or adult testis, especially as to whether testicular development affects reproductive behavior, are unclear, and contradictory results have been reported not only in different species but also in the same animal model. For example, results of very early studies showed that growth of the testis and epididymis was only slightly reduced in young rats.It can be supposed that an enhanced thyroid activity during the humid warm season in such environments is functional for the animals facing the increased availability of food (quantity and quality), following the seasons characterised by food shortage. Blood TH concentrations were high in spring (increasing day length) and low in autumn (decreasing day length), which was not fully explained by the changes in environmental temperature.

Nazifi ${ }^{(22)}$ reported that in a study to determine whether there was any correlation between serum thyroid hormones, lipids, lipoproteins and the activities of erythrocyte superoxide dismutase (SOD) and glutathione peroxidase (GPX) in adult nonpregnant uniparous Iranian pure bred fat-tailed ewes. Blood samples $(10 \mathrm{~mL})$ were taken room the jugular vein of 30 clinically healthy Iranian adult nonpregnant uniparous ewes at 8 a.m during 6 consecutive days of summer with a mean ambient temperature of $40^{\circ} \mathrm{C}$. The serum was analyzed for thyroxine (T4), tri-iodothyronine (T3), free thyroxine (fT4), free tri-iodothyronine (fT3), cholesterol, triglyceride, lipoproteins [high density lipoprotein (HDL-cholesterol), low density lipoprotein (LDL-cholesterol) and very low density lipoprotein (VLDL-cholesterol)], SOD and GPX activity. There were no significant differences in serum thyroid hormones, lipids, lipoproteins and antioxidant enzymes in different days $(\mathrm{P}>0.05)$. In addition, there were no significant correlations between serum thyroid hormones, lipids, lipoproteins and antioxidant enzymes in different days $(\mathrm{P}>0.05)$.

In intercuts, the administration of $\mathrm{T} 4$ resulted in a decrease in serum gonadotropins levels Schneider ${ }^{(23)}$. However, Chandrasekgar ${ }^{(24)}$. Stated that it would appear that $\mathrm{T} 4$ does not exert a direct effect on spermatogensis in mature rats or rams. Meanwhile,VanHaasteret Reported that triiodothyronine (T3) stimulates Sertoli differentiation and shortens the period of mitotic division. Ramachandran ${ }^{(25)}$ Showed that the effects of transient neronatal hypothyroidism (HPOT) on adult testis size and serum hormone profiles were evaluated in the Charles foster strain of rats maintained under the temperature of 21 degrees $\mathrm{C}$ (HPOTL) or of 34 degrees C (HPOTH) or of 34 degree C (HPOTH). Serum testosterone, concentrations activities was reduced in both groups of the HPOT rates after 35 and 45 days. Turek $^{(12)}$. Showed that neonatal treatment with the reversible goitrogen 6-N-propyl-2-thiouricil (PTU) had no effect and serum testosterone levels were 
similar in treated and control males. Control males demonstrated in creased testosterone levels were observed in all males. Earlier than observed in treated males. These results demonstrate that the neonatal PUT treatment induced increases in sperm production.

Zamoner et al. ${ }^{(26)}$. Found that in study investigated the effect of some thyroid gland modulating drugs (eltroxin, thyroid hormone agonist and carbimazol thyroid hormone antagonist) on the gonadal activity and some reproduction aspects under the seasonal variation. This was achieved through the determination of serum thyroid stimulating hormone (TSH), thyroid hormones (T3 and T4), adenosine triphosphate (ATP), glucose, lipid profile, total protein and free and total testosterone in carbimazole and eltroxine treated rats at different intervals (1,2 and 3 months) during summer and winter seasons.

\section{Material and methods}

Carbimazol: The anti-thyroid agent; Carbimazol (Ethyl 3-methyl-2-thioxo-4-imidaz-dine-1carboxylate) was administered orally at a dose of $15 \mathrm{mg} / \mathrm{kg} \mathrm{B}$.WT. for up to 90 days to observe the influence of Carbimazol on the blood serum level of thyroid hormones; Triiodothyronine , (T3) and Thyroxine (T4).

Eltroxin: (L-thyroxine sodium) was given orally at a dose of $15 \mu \mathrm{g} / \mathrm{kg}$ B.WT. For up to 90 days. Blood samples were withdrawn at intervals of 1,2 and three months.

Experimental animals

A total number of 90 adult male albino rats (12-15 weeks of age) weighing from 150-180 gm were used in this study. The rats were raised in the National Organization for Drug Control and Research animal's house and were kept under normal laboratory conditions for three weeks prior to the experiments for adaptation. The rats were fed on a normal diet..Rats were randomly divided into two equal main groups (90 rats each).Each main group was divided into equal three groups.Subgroup 1 Served as control and fed on normal diet (30 rats).Subgroup 2 rats fed on normal diet + Carbimazol (30 rats) and Subgroup 3 rats fed on normal diet + Eltroxin (30 rats). The intervals lies on the summer season which represents the hot weather (June -July and August). Are corresponding to the first, second and third intervals respectively.

Blood sampling:

Initial blood samples were withdrawn before treatment (0-time) and then after 30 days in a Subgroup 1, 60 days in a Subgroup 2 and 90 days in a Subgroup 3. Samples were collected from the retro-orbital venous plexus. The blood samples were collected in a clean centrifuge tubes which were kept at room temperature for approximately one hour to allow clotting. Then the tubes were centrifuged and the clear serum was carefully withdrawn and stored at $-20^{\circ} \mathrm{C}$ for the subsequent biochemical analysis.

\section{Biochemical analysis}

Determination of serum total cholesterol, serum triglycerides, T3, T4, TSH, total testosterone, free testosterone, and ATP by (ELIFA). Statistical analysis was carried out using SPSS program. One way analysis of variance and Duncan's Multiple Range Test (Procedure GLM of SAS).

\section{Results and discussion}

Table (1). Effect of Carbimazol and Eltroxin on Total Cholesterol Level in Adult Male Rats During winter.

\begin{tabular}{|l|c|c|c|}
\hline \multirow{2}{*}{ Groups } & \multicolumn{3}{|c|}{ Total Cholesterol } \\
\cline { 2 - 4 } & 1St Interval & 2St Interval & 3St Interval \\
\hline \multirow{2}{*}{ Control-1 } & 66.2 & 66.43 & 67.92 \\
& \pm 0.85 & \pm 3.88 & \pm 3.64 \\
\hline & 66.4 & & 74.78 \\
& \pm 1.39 & 66.82 & \pm 1.91 \\
Carbimazol-1 & $(100.3 \%)$ & $\pm 1.35(\mathrm{a} 100.6 \%)$ & $(\mathrm{a} 110.1 \%)$ \\
\hline & 61.2 & 62.45 & 71.81 \\
& \pm 3.94 & \pm 2.32 & $\pm 0.77 \mathrm{~b}$ \\
Eltrxin-1 & $(\mathrm{a} 92.4 \%)$ & $(94.0 \%)$ & $(105.7 \%)$ \\
\hline
\end{tabular}

post-t Data are expressed as means \pm S.E

Table (1).The rat was treatment by Carbimazol showed that serum Cholesterol level was significantly increased in the third interval compared with control group. Also the Carbimazol treated in the first and second interval no significantly. On the other hand the rat was treatment by Eltroxine showed that decreased Cholesterol level in the first and second interval compared with control group while the third interval caused increased in the Cholesterol level compared with control group.

Table (2).Effect of Carbimazol and Eltroxin On triglyceride Level mg/dL in Adult Male Rats During winter

\begin{tabular}{|l|c|c|c|}
\hline \multirow{2}{*}{ Groups } & \multicolumn{3}{|c|}{ Triglyceride } \\
& 1St Interval & 2St Interval & 3St Interval \\
\hline \multirow{2}{*}{ Control-1 } & 42.99 & 43.77 & 43.16 \\
& \pm 2.05 & \pm 2.09 & \pm 2.06 \\
\hline & 50.25 & 55.68 & 41.00 \\
& $\pm 2.40(116.9 \%)$ & \pm 2.66 & \pm 1.96 \\
Carbimazol-1 & 42.61 & $(\mathrm{a} 127.2 \%)$ & 46.63 \\
& \pm 2.03 & $45.21 \pm 2.16(103.3 \%)$ & $\pm 2.23 \mathrm{~b}(106.9 \%)$ \\
\hline
\end{tabular}

Data are expressed as means \pm S.E

Rats treatment by Carbimazol in Table (2) the experimental data indicated that significant increased serum triglyceride in the first and second interval but the third interval caused significant decreased compared with control group. Furthermore the groups traded by Eltroxine in the 
second and third interval found that increased in serum triglyceride.

Table (3).Effect of Carbimazol and Eltroxin On glucose Level $\mathrm{mg} / \mathrm{dL}$ in Adult Male Rats During winter

\begin{tabular}{|c|c|c|c|}
\hline \multirow{2}{*}{ Groups } & \multicolumn{3}{|c|}{ Glucose } \\
\cline { 2 - 4 } & $1^{\text {St }}$ Interval & $2^{\text {St }}$ Interval & $3^{\text {St }}$ Interval \\
\hline \multirow{2}{*}{ Control-1 } & 77.53 & 77.78 & 76.66 \\
& \pm 0.51 & \pm 0.51 & \pm 0.50 \\
\hline & 70.24 & 87.80 & 89.39 \\
& \pm 0.46 & \pm 0.58 & \pm 0.58 \\
Carbimazol-1 & $(\mathrm{a} 90.6 \%)$ & (a $112.9 \%)$ & (a $116.6 \%)$ \\
\hline & 77.47 & 82.60 & 84.29 \\
& \pm 0.51 & \pm 0.54 & \pm 0.55 \\
Eltrxin-1 & (a 99.9\%) & (a $106.2 \%)$ & (b $109.9 \%)$ \\
\hline
\end{tabular}

Data are expressed as means \pm S.E

As indicated in Table (3). The compiled data revealed that in groups treated by Carbimazol. Increased the second and third intervals compare with control. While the first interval caused decreased compare with control group. The effect of Eltroxine in second and third intervals caused Increased. But the first interval no change compare with control group.

Table (4) Effect of Carbimazol and Eltroxin on Total protein Level g/dLin Adult Male Rats During winter.

\begin{tabular}{|c|c|c|c|}
\hline \multirow{2}{*}{ Groups } & \multicolumn{3}{|c|}{ Total protein } \\
\cline { 2 - 4 } & \multirow{2}{*}{$1^{\text {St }}$ Interval } & $2^{\text {St }}$ Interval & $3^{\text {St Interval }}$ \\
\hline \multirow{2}{*}{ Control-1 } & 7.24 & 7.15 & 7.22 \\
& \pm 0.07 & \pm 0.06 & \pm 0.07 \\
\hline & 7.22 & 7.21 & 7.95 \\
& \pm 0.07 & \pm 0.06 & \pm 0.08 \\
Carbimazol-1 & $(97.3 \%)$ & $(100.8 \%)$ & $(\mathrm{a} 110.1 \%)$ \\
\hline & 5.76 & 7.27 & 7.29 \\
& \pm 0.05 & \pm 0.06 & \pm 0.07 \\
Eltrxin-1 & (a $100.7 \%)$ & $(101.6 \%)$ & $(100.9 \%)$ \\
\hline
\end{tabular}

Data are expressed as means \pm S.E.

The biochemical parameters of males rats shown in table(4). The serum concentrations of total protein were significant increase in the third interval when compared with control, while the first and second intervals caused no change in concentration of total protein levels were significantly higher $(\mathrm{p}<0.05)$ in Carbimazol treated. On the other hand the rat was treatment by Eltroxine showed that Significant decreased compared with the control group in the first interval. While the second and the third intervals caused no change in concentration of total protein levels. In the present study, administration of carbimazol (CBZ) resulted in an increase in serum levels of total protein and a decrease in albumin level. The increase in total protein and globulins

levels may be related to increased rate of synthesis in liver.

Table (5).Effect of Carbimazol and Eltroxin on T3 Level ( $\mu \mathrm{g}$ /dL) in Adult Male Rats During winter.

\begin{tabular}{|c|c|c|c|}
\hline \multirow{2}{*}{ Groups } & \multicolumn{3}{|c|}{ T3 } \\
\cline { 2 - 4 } & $1^{\text {St }}$ Interval & $2^{\text {St }}$ Interval & $3^{\text {St }}$ Interval \\
\hline \multirow{2}{*}{ Control-1 } & 49.37 & 48.48 & 47.66 \\
& \pm 1.08 & \pm 0.70 & \pm 0.35 \\
\hline & 50.18 & 49.20 & 50.97 \\
& \pm 1.10 & \pm 0.71 & \pm 0.37 \\
Carbimazol-1 & $(101.6 \%)$ & $(101.4 \%)$ & $(106.9 \%)$ \\
\hline & 52.69 & 49.58 & 49.84 \\
& $\pm 1.15(\mathrm{a}$ & \pm 0.72 & $\pm 0.37(\mathrm{a}$ \\
Eltrxin-1 & $106.7 \%)$ & $(102.2 \%)$ & $104.6 \%)$ \\
\hline
\end{tabular}

Data are expressed as means \pm S.E

The serum concentration of T3 Level in Adult Male rats during summer are shown in table (5). Mean serum T3 Level were significantly higher in the third interval when the first and second interval caused slightly increased compared with control groups in Carbimazol treated. These results which traded with Eltroxine indicated that significant increased in all groups' treatment compared with the control.

Table (6).Effect of Carbimazol and Eltroxin on T4 Level( $\mu \mathrm{g}$ /dL) in Adult Male Rats During winter

\begin{tabular}{|c|c|c|c|}
\hline \multirow{2}{*}{ Groups } & \multicolumn{3}{|c|}{$\mathrm{T} 4$} \\
\cline { 2 - 4 } & $1^{\text {St }}$ Interval & $2^{\text {St }}$ Interval & $3^{\text {St }}$ Interval \\
\hline \multirow{2}{*}{ Control-1 } & 4.82 & 4.44 & 4.55 \\
& \pm 0.07 & \pm 0.07 & \pm 0.07 \\
\hline & 5.02 & 5.27 & 3.64 \\
& \pm 0.07 & \pm 0.08 & \pm 0.06 \\
Carbimazol-1 & $(104.1 \%)$ & $(\mathrm{a} 118.7 \%)$ & $(\mathrm{a} 80.0 \%)$ \\
\hline & 5.04 & 5.35 & $6.69 \pm 0.10$ \\
& \pm 0.07 & \pm 0.08 & $(\mathrm{~b} 143.7 \%)$ \\
\hline
\end{tabular}

Data are expressed as means \pm S.E.

Table (6).The serum of $\mathrm{T} 4$ level were significant increase in the first and second intervals but the third interval caused significant decreased camper with control groups were traded with Carbimazol. Thereafter the treated group by Etroxine caused significantly increased in the first, second and third intervals compared with the control group.

Table (7).Effect of Carbimazol and Eltroxin on TSH Level( $\mu \mathrm{IU} / \mathrm{ML})$ in Adult Male Rats During winter

\begin{tabular}{|l|c|c|c|}
\hline \multirow{2}{*}{ Groups } & \multicolumn{3}{|c|}{ TSH } \\
\cline { 2 - 4 } & $1^{\text {St }}$ Interval & $2^{\text {St }}$ Interval & $3^{\text {St }}$ Interval \\
\hline \multirow{2}{*}{ Control-1 } & 0.34 & 0.34 & 0.34 \\
& \pm 0.001 & \pm 0.001 & \pm 0.001 \\
\hline & 0.35 & 0.43 & 0.36 \\
Carbimazol-1 & \pm 0.001 & \pm 0.001 & \pm 0.001 \\
& $(102.9 \%)$ & $(\mathrm{a} 126.4 \%)$ & $(102.9 \%)$ \\
\hline \multirow{2}{*}{ Eltrxin-1 } & 0.37 & 0.36 & 0.35 \\
Data are expressed as means \pm S.E. & \pm 0.001 & \pm 0.001 \\
& \pm 0.001 & $(105.9 \%)$ & $(102.9 \%)$ \\
\hline
\end{tabular}


Result in Table (7). Showed that carbimazol treatment caused significant Increase in serum TSH level after the second interval compared with control. While slightly significant Increase after in the first and third intervals compared with control group. Eltroxine caused significant decrease in serum TSH level after the first intervals. And caused slightly significant increase in serum TSH after all intervals.compared with control group.

Table (8).Effect of Carbimazol (mg/dL) and Eltroxin ( $\mu \mathrm{g} / \mathrm{dL})$ on Total testosterone Level in Adult Male Rats During winter

\begin{tabular}{|l|c|c|c|}
\hline \multirow{2}{*}{ Groups } & \multicolumn{3}{|c|}{ Total Testosterone } \\
\cline { 2 - 4 } & $1^{\text {St }}$ Interval & $2^{\text {St }}$ Interval & $3^{\text {St }}$ Interval \\
\hline \multirow{2}{*}{ Control-1 } & 6.21 & 6.45 & 6.52 \\
& \pm 0.24 & \pm 0.25 & \pm 0.25 \\
\hline & 5.46 & 7.16 & 5.75 \\
& \pm 0.21 & \pm 0.28 & \pm 0.22 \\
Carbimazol-1 & $(\mathrm{a} 87.9 \%)$ & $(\mathrm{a} 111.0 \%)$ & $(88.1 \%)$ \\
\hline & 8.03 & 8.18 & 9.76 \\
& \pm 0.31 & \pm 0.32 & \pm 0.37 \\
Eltrxin-1 & (b $128.9 \%)$ & (a $126.8 \%)$ & (a $149.6 \%)$ \\
\hline
\end{tabular}

Data are expressed as means \pm S.E.

Result in Table (8) Investigated that carbimazol treatment caused significant Increase in serum Total testosterone level after the second interval compared with control while significant decreased after the first and third intervals compared with control group. Eltroxine caused significant increase in serum Total testosterone level after the all intervals. Compare with control group.

Table (9).Effect of Carbimazol(mg/dL) and Eltroxin( $\mu \mathrm{g} / \mathrm{dL})$ On free testosterone Level in Adult Male Rats During winter

\begin{tabular}{|c|c|c|c|}
\hline \multirow{2}{*}{ Groups } & \multicolumn{3}{|c|}{ free testosterone } \\
\cline { 2 - 4 } & $1^{\text {St }}$ Interval & $2^{\text {St }}$ Interval & $3^{\text {St Interval }}$ \\
\hline \multirow{2}{*}{ Control-1 } & 0.67 & 0.66 & 0.66 \\
& \pm 0.024 & \pm 0.02 & \pm 0.02 \\
\hline & $0.59 \pm$ & 0.59 & 0.59 \\
& 0.02 & \pm 0.02 & \pm 0.02 \\
Carbimazol-1 & $(\mathrm{a} 88.0 \%)$ & $(\mathrm{a} 89.3 \%)$ & $(\mathrm{a} 89.3 \%)$ \\
\hline & 0.74 & 0.56 & 0.57 \\
& \pm 0.02 & \pm 0.02 & \pm 0.02 \\
Eltrxin-1 & $(\mathrm{a} 110.9 \%)$ & $(\mathrm{a} 84.8 \%)$ & $(\mathrm{a} 86.3 \%)$ \\
\hline
\end{tabular}

Data are expressed as means \pm S.E.

Table (9).The serum concentrations of free testosterone Level were significant decrease in the all intervals compared with the control group. Were significantly higher $(\mathrm{p}<0.05)$ in carbimazol treated. On the other hand the rats were treatment by Eltroxine showed that Significant decreased in the all intervals compared with the control group.
Table (10).Effect of Carbimazol and Eltroxin on ATP Level in Adult Male Rats During winter

\begin{tabular}{|c|c|c|l|}
\hline \multirow{2}{*}{ Groups } & \multicolumn{3}{|c|}{ ATP } \\
\cline { 2 - 4 } & $1^{\text {St }}$ Interval & $2^{\text {St }}$ Interval & $3^{\text {St }}$ Interval \\
\hline \multirow{2}{*}{ Control-1 } & 21.44 & 22.49 & 18.84 \\
& \pm 1.42 & \pm 1.49 & \pm 1.25 \\
\hline & 37.13 & 17.11 & 14.80 \\
& $\pm 2.46 \mathrm{a}$ & \pm 1.1 & \pm 0.9 \\
Carbimazol-1 & $(176.1 \%)$ & $(376.1 \%)$ & $(878.5 \%)$ \\
\hline & 16.34 & 18.22 & 28.36 \\
& $\pm 1.08 \mathrm{~b}$ & \pm 1.21 & $\pm 1.88 \mathrm{a}$ \\
Eltrxin-1 & $(76.21 \%)$ & $(81.0 \%)$ & $(150.5 \%)$ \\
\hline
\end{tabular}

Data are expressed as means \pm S.E.

The serum concentration of ATP Level in Adult Male rats during summer are shown in table (10). Mean serum ATP Level were significantly higher in the first interval when the second and third intervals caused slightly increased compared with control groups in carbimazol treated. These results which traded with Eltroxine indicated that significant increase in third interval when the first and second intervals caused Significant decreased compared with the control

\section{Discussion}

Serum cholesterol was consistently negatively correlated with serum thyroxine and triiodothyronine levels. There is a paucity of information about the effects of hypo- and hyperthyroidism on the serum cholesterol, triglyceride and phospholipid concentrations of Nubian goats Ibrahim $^{(27)}$. While the first interval caused no significant $^{(3)}$.

The present study was therefore conducted to estimate the normal values of serum lipids and lipoproteins (cholesterol, triglyceride,total lipids, HDL-cholesterol,LDL-cholesterol and VLDLcholesterol) and their correlation with thyroid hormones in clinically healthy male goats, as no information is currently available. Thyroid hormones exert profound effects in the regulation of glucose homeostasis. These effects include modifications of circulating insulin levels and counter-regulatory hormones, intestinal absorption, hepatic production and peripheral tissues (fat and muscle) uptake of glucose. Viguerie ${ }^{(28)}$. For effective execution of glucose homeostasis, synthesis and release of thyroid hormones must be adequately regulated in the body. Both thyroid disorders and substances that disrupt the synthesis and secretion of thyroid hormone have a major impact on glucose control. When thyroid dysfunction ensues, the glucose homeostatic balance is broken. Synthetic thyroactive drugs are produced for treatment of thyroid disorders, such as carbimazole, a pro-drug of methimazole and propylthiouracil both used in the treatment of hyperthyroidism. Gabriela $\mathrm{B}^{(29)}$.

The decrease in serum albumin level obtained in the present study is attributable to an increase in its urinary excretion. In hypothyroid rats, the urine 
excretion was increased and the urinary concentrating ability was decreased Holmes and Discala $^{(30)}$ The present results are in agreement with Nogues who reported that low T3 level was associated with hypoalbuminaemia in humans.

Several compounds have the ability to inhibit thyroid hormones synthesis with various mechanisms of action. The antithyroid drugs interfere directly with the synthesis of thyroid hormones Taurog A. ${ }^{(31)}$ While inhibitors block the iodide transport mechanism Ermans ${ }^{(32)}$.Iodine in high concentration suppresses the thyroid Brabant (33) and radioactive iodine damages the gland with ionizing radiations Doi ${ }^{(34)}$

Mannisto ${ }^{(35)}$ reported that in rats receiving graded doses of the antithyroid drugs PTU and MMI, the concentrations of T3 and T4 decreased and serum TSH level increased. Chronic administration of Carbimazol to hyperthyroid cats depressed the serum total thyroxin level and decreased the heart rate and respiratory rate. Carbimazol also induced hematological changes which included lymphocytosis and agranulocytosis.

Reported that methimazole at 10 and $25 \mathrm{mg} / \mathrm{litre}$ in drinking water decreased T4 and increased TSH in rats. The findings in the present study are in agreement with previous studies which demonstrated that basal metabolic rate (BMR), $\mathrm{O}_{2}$ consumption and energy expenditure decreased in thyroidectomized rabbits and indicated that hypothyroid rats could not maintain their body core temperature when exposed to cold and the abnormality was rapidly corrected by administration of $\mathrm{T} 4^{(36)}$

Thyroid hormonesincrease the number of Leydig cell luteinizing hormone (LH) receptors, stimulate Leydig cell testosterone production and secretion. LH is necessary for cellular maintenance of Leydig cells Maran ${ }^{(37)}$ and Maran, ${ }^{(38)}$. The trophic factors traditionally associated with the growth and maturation of the testis and its constituent cell types are follicle stimulating hormone $(\mathrm{FSH})$ and $\mathrm{LH}^{(38)}$. LH triggers differentiation of Leydig cells and stimulates testosterone production and secretion by Leydig cells Mann and Fraser ${ }^{(39)}$. FSH is the major endocrine factor regulating mitogenesis and differentiation of Sertoli cells and the onset of secretary activity ${ }^{(40)}$. The objective of the present study was to investigate the effects of hypo- and hyperthyroidism on seminiferous tubules morphology, number of spermatogenic, Leydig, Sertoli and sperm cells in the adult male rats.

Fineberg ${ }^{(41)}$.Nine sexually mature rams, three shall, three Afshari and three Zandi were used in this study. Semen of rams was collected twice per month during the four seasons of the year and blood samples were obtained via jugular vein. Seminal characteristics, scrotal dimension and blood parameters were measured at 2 week intervals. Time of the year significantly $(\mathrm{p}<0.05)$ affected the volume of semen, sperm concentration, percentage live sperm, percentage abnormal sperm, sperm mass motility, total sperm number, scrotal circumference, relative testis volume and serum levels of testosterone, triiodothyronine and thyroxine. All of semen characteristics, except sperm abnormality, were high in summer months than at other months of the year $(p<0.05)$.

From our results, levothyroxine treatment appears to have created, understandably, elevation of thyroid hormone levels thus mimicking a hyperthyroid state. In this state, there is likely massive arrival of glucose to the peripheral cells that overwhelms the Kreb's cycle resulting in an increased metabolism of glucose through the nonoxidative pathway. Lactate produced in large quantity in the cells returns to the liver and participates in the Cori cycle where four ATP molecules are wasted for each glucose molecule created. This result agreement with Fineberg ${ }^{(41)}$, who showed that weight depends on the energy intake and expenditure. When energy intake exceeds output, the excess energy is stored in the body as carbohydrates, protein or fats and this causes a gain in body weight. The converse is also true when energy expenditure exceeds energy intake, body weight will decrease. It has been appreciated for a very long time that there is a complex relationship between thyroid disease, body weight and metabolism. Thyroid hormone regulates metabolism in both animals and humans. Metabolism is determined by measuring the amount of oxygen used by the body over a specific amount of time. If the measurement is made at rest, it is known as the basal metabolic rate (BMR). Indeed, measurement of the BMR was one of the earliest tests used to assess a patient's thyroid status. Hypothyroid patients were reported to present with low BMR while patients with hyperthyroidism had high BMR, American Thyroid Association.

The results of the peroxidation of fatty acids containing three or more double bonds. The MDA product can crosslink membrane elements and affect the ion exchange across the cell membranes, which results in changes in ion permeability and enzyme activity. In this study, the MDA level was found to be significantly higher in the E. coliinfected chickens than in the non-infected birds, suggesting that the

\section{References}

1. Nolple R. Immunoregulation in autommune thyroid disease .NEngl J Med. 1987, 316:44-46

2. Reinwein D. A prospective randomized trial of antithyroid drug dose in Graes disease theraby. J clin Endocrinol metab. 1993, 76:1516-1521.

3. Vigumarsson S. Plasma lipoprotein alterations in thyroid dysfunction. Roles of lipoprotein lipase, hepatic lipase and LCAT. Acta Endocrinol Suppl (Copenh). 1983, 255:1-52

4. Serdaru M, Nicolae I, Enculescu M, Bota A and Bolocan E. Seasonal variations of some hematological and biochemical parameters of the Carpathian Romanian buffaloes. I. The Winter 
Period. Scientific Papers: Animal Science and Biotechnology. 2011, 44(1):94-98.

5. Tuffery AR and Redmond O. Thyroid proliferation, body weight, thyrotropin and thyroid hormrnes in chronic antithyroid (Carbimazol) treatment in rats. J Anat.1983, 1:37-47 .

6. Vinsova J, Hrabalek A, Vazura Strbac, Stolba $P$ and Nedvidkova J. The effect of 1-p-bromphenyl-5-mercapto1,2,3,4-tetrazole (Br FMT) on thyroid gland function in rats .Cesk Farm.1991, 40(2):75-77.

7. VanHaster LH, de Jone F, Doctter R, de Rooij DG. High neonatal triiodthyronine levels reduce the period of sertoli cell proliferation and accelerate tubular lumen formation in the rat testis,and increase serum inhibit levels .Endocrinology. 1993, (2):755-60

8. Sawaya S and Lunn A. Lowering of plasma triiodothyronine level and sympathetic activity dose not alter hypoalbiominaemia in rats fed on a diet of low protein concentration british - journal - of -Natrition. 1998, 79, 455- 462.

9. Cigankova A and Bekeova E. The influence of administration of preparation Carbimazol (thyroid antigonists) on the morphology and function of ram testes .Folia - veterinarian 1999, 1:3-7.

10. Pinaki Dutta, Anil Bhansali, Rama Walia, Niranjan Khandelwal, Sambit Das and Shariq Rashid Masoodi. Weight homeostasis \& its modulators in hyperthyroidism before \& after treatment with carbimazole Indian J Med Res 2012, 5: 242-248. 11. Ayub $M$ and level M. Structure activity relation of the inhibition of human placental aromatase by imidazol drugs including ketoconazol . Journal of steroid biochemistry. 1996, 31: $65-72$.

12. Turek FW, Ackland JD and Schwartz NB. Developmental hormonal profiles accompanying the neonatal hypothyroidisminduced increase in adult testicular size and sperm production in the rat. Endocrinology. 1992, 131(2):559-565.

13. El-Wardany, Eman F, El-Daly, AH, Abd El-Gawad AEA, Hemid and Nafisa A Abd El-Azeem. Effect of Thyroid Activity Modulation on Some Histological and Biochemical Aspects in Broiler Chicks American-Eurasian J. Agric. \& Environ. Sci.,2011, 11 (6): 893-902,

14. Hazelwood RL. (2012). Pancreas Pp. 539-555. In: Sturkie's Avian Physiology, 5th ed. G Causey Whittow, ed. Academic Press. CA.

15. Mandel SJ, Brent GA and Larsen PR. Levothyroxine therapy in patients with thyroid disease.nn Intern Med.Sep 1993, 119(6):492-502.

16. Toft A. Thyroxine therapy. N Engl J Med.1994, 21;331(3):174-80.

17. Hansson $P$, Valdemarsson $S$ and Nilsson-Ehle $P$. Experimental hyperthyroidism in man: effects on plasma lipoproteins, lipoprotein lipase and hepatic lipase.Horm Metab Res. 1983, 15(9):449-52

18. Boston RC, Frank N1, Sommardahl CS, Eiler H, Webb LL and Denhart JW. Effects of oral administration of levothyroxine sodium on concentrations of plasma lipids, concentration and composition of very-low-density lipoproteins, and glucose dynamics in healthy adult mares. Am J Vet Res. 2005, 66(6):1032-8.

19. Ganong W.F. (1995). Review of Medical physiology,17ed.,Middle East Edition,Librairie du Liban pub.,pp.298.

20. Dubey RK, Zhang HY, Reddy SR, Boegehold MA and Kotchen TA. (1993). Pioglitazone attenuates hypertension and inhibits growth of renal arteriolar smooth muscle in rats.Am J Physiol. 1993, 265, 726-32.

21. Weiss SR and Burns JM. The effect of acute treatment with two goitrogens on plasma thyroid hormones, testosterone and testicular morphology in adult male rats.Comp Biochem Physiol A Comp Physiol. 1988, 90(3):449-52.

22. Nazifi, M, Rowghani M, Hasankhani F, Hasanshahi and Ghafar N. Studies on the physiological relationship between thyroid hormones, serum lipid profile and erythrocyte antioxidant enzymes in clinically healthy iranian fat-tailed sheep bulgarian journal of veterinary medicine. 2007, 3:161-167.

23. Schneider BH, Edwards JG, Hartman NF. Hartman interferometer: versatile integrated optic sensor for label-free, real-time quantification of nucleic acids, proteins, and pathogens.Clin Chem. 1997, 43(9):1757-63.

24. Chandrasekgar Y, Holland MK, D'Occhio MJ, Setchell BP. Spermatogenesis, seminal characteristics and reproductive hormone levels in mature rams with induced hypothyroidism and hyperthyroidism.J Endocrinol. 1985, 105(1): 39-46.

25. Ramachandran AV. Lagu SK, Bhavsar NG, Sharma RK. Neonatal hypothyroidism-induced changes in rat testis size, dependence on temperature. Neuro Endocrinol Lett. 2005, 26(6):780-8.

26. Zamoner A, Funchal C, Jacques-Silva MC, Gottfried C, Barreto Silva FR, Pessoa - Pureur R. Thyroid hormones reorganize the cytoskeleton of glial cells through Gfap phosphorylation and Rhoa - dependent mechanisms. Cell Mol Neurobiol. 2007, 27(7):845-65

27. Ibrahim RE, Magland MA, Adam SEI, Mirghani TE and Wasfi IA. The effects of altered thyroid status on lipid metabolism in Nubian goats.Comparative - biochemistry -andphysiology. 1984,3 :507-512.

28. Viguerie N, Millet L, Avizou S, Vidal H, Larrouy D, Langin D. Regulation of human adipocyte gene expression by thyroid hormone.J Clin Endocrinol Metab. 2002, 87(2):630-4

29. Gabriela B. British Journal of Diabetes and Vascular Disease. 2010; 10(4):172-177.

30. Taurog A. The mechanism of action of the thioureylene antithyroid drugs. Endocrinology. 1976, 98(4):1031- 46.

31. Ermans AM, Camus M. Modifications of thyroid function induced by chronic administration of iodide in the presence of "autonomous" thyroid tissue. JBSR. 1972, 4; 354-367.

32. Brabant G, Biester A, Münte TF, von zur Mühlen A and Heinze HJ. Thyroid hormones influence perceptual processing in a visual search paradigm. Acta Med Austriaca 1992, 1:103-5. 33. Doi SA. Usefulness of the diagnostic total body scan in differentiated thyroid cancer.J Clin Endocrinol Metab. 2001, 86 (2):949-50.

34. Männistö PT, Kokkonen J and Ranta T. Effects of acute hypotension and hypertension on serum TSH concentrations in male rats.cta Physiol Scand. 1979, 107(2):105-7.

35. Capasso G, De Santo NG and Kinne R. Thyroid hormones and renal transport: cellular and biochemical aspects.Kidney Int. 1987, 32(4):443-51.

36. Maran RR, Arunakaran J, Jeyaraj DA, Ravichandran K, Ravisankar B and Aruldhas MM. Transient neonatal hypothyroidism alters plasma and testicular sex steroid concentration in puberal rats.Endocr Res. 2002, 26(3):411-29.

37. Maran RR. Thyroid hormones their role in testicular steroidogenesis. Arch Androl. 2003, 49(5):375-88.

38. Mann DR and Fraser HM. The neonatal period: a critical interval in male primate development. J Endocrinol . May. 1999, 149(2):191-7.

39. Jegou B and Sharpe RM.(1993). Paracrine mechanisms in testicular control. InMolecular Biology of the Male Reproductive System, pp 271-310. Ed. DM De Kretser. New York: Academic Press.

40. Tajangookeh HD, Shahneh AZ, Shahrebabak MM and Shakeri M. Monthly variation of plasma concentrations of testosterone and thyroid hormones and reproductive characteristics in three breeds of Iranian fat-tailed rams throughout one year.Pak J Biol Sci. 2007, 1:3420 - 4.

41. Fineberg NA, Potenza MN, Chamberlain SR, Berlin H and Menzies L. Bechara Neuropsychopharmacology. 2010, 35: 591604. 